\title{
Progress of engineered antibody-targeted molecular imaging for solid tumors (Review)
}

\author{
HONG ZHAO, KEMI CUI, ANDREA MUSCHENBORN and STEPHEN T.C. WONG \\ Department of Radiology, Methodist Hospital, Weill Medical College, Cornell University, Houston, TX 77030, USA
}

Received November 16, 2007; Accepted December 3, 2007

\begin{abstract}
Engineered antibodies, with their high specificity and affinity for their target antigens, as well as their reduced size and multivalent design, can be tailored to carry radionuclide magnetic, luciferase or fluorescent probes for specific attachment to tissue cells, extracellularly or intracellularly, for PET, SPECT, MRI, optical and ultrasonic imaging. The antigen-specific imaging agents of engineered antibodies have deep tissue penetration, high tissue retention and fast blood clearance, which are desirable properties for the rapid imaging of tumors with high specificity and resolution in pre-clinical or clinical imaging studies.
\end{abstract}

\section{Contents}

1. Introduction

2. PET imaging

3. SPECT imaging

4. MRI imaging

5. Optical fluorescence and bioluminescence imaging, mainly

6. Ultrasound imaging

7. Conclusion

\section{Introduction}

Monoclonal antibodies have long been eyed as a potential new class of therapeutics targeting cancer and other diseases with their high-specificity targeting feature. Throughout the 1990's, innovative recombinant antibody technologies led to a wave of approvals by the FDA for therapeutic immunoglobulin (Ig) and Fab (fragment antigen binding) molecules. These developments have continued; there are presently 18 engineered antibody products on the market, and more than 100 are

Correspondence to: Dr Stephen T.C. Wong, Department of Radiology, Methodist Hospital, Weill Cornell University, Houston, TX 77030, USA

E-mail: stwong@tmhs.org

Key words: engineered antibody, molecular imaging, solid tumor still being tested. It is predicted that by 2008 they will account for more than $30 \%$ of all revenues in the biotechnology market $(1,2)$.

Molecular imaging is a powerful tool in the investigation of molecular interactions for drug discovery and development, and also provides important diagnostic and prognostic information affecting patient management in the clinical setting. However, the use of molecular imaging for diagnosis has not been widely adopted, in part due to a lack of suitable targeting agents (3).

Engineered antibodies, especially intermediate engineered antibody fragments such as single-chain variable fragments ( $\mathrm{scFv}, 25 \mathrm{kDa}$ ), diabodies (dimers of scFvs, $55 \mathrm{kDa}$ ) and minibodies (scFvs fused to single $\mathrm{Fc}$ domains, $80 \mathrm{kDa}$ ) possess the unique properties of improved tumor penetration, faster clearance kinetics and increased tumor-to-blood ratios. They promise specific delivery to tissue cells for PET (positron emission tomography), SPECT (single photon emission computed tomography), MRI (magnetic resonance imaging), optical (fluorescence and bioluminescence) and ultrasound imaging, once tagged with different imaging probes.

This review will focus on the recent use of engineered antibodies for the non-invasive in vivo molecular imaging of solid tumors, and for the monitoring of tumor progression in response to cancer therapy in pre-clinical animal models and clinical trials.

\section{PET imaging}

Although most clinical PET studies (95\%) are based on ${ }^{18} \mathrm{~F}-\mathrm{FDG}$, recent interest has arisen regarding the development of specific imaging agents, such as probes with engineered antibodies, as they make it possible to visualize tumors that exhibit low metabolic activity and cannot therefore be detected by conventional ${ }^{18} \mathrm{~F}-\mathrm{FDG}$ PET.

Previous evaluation of the targeting and biodistribution of $\mathrm{scFv}$ fragments specific to carcinoembryonic antigen (CEA) or tumor-associated glycoprotein demonstrated localization to the tumor, but activity levels were insufficient $(4,5)$. More recently, the results of Sundaresan et al (6) provided evidence that ${ }^{124}$ I-radiolabeled anti-CEA diabody and minibody in $\mathrm{CEA}^{+}$ LS174T xenografts have strong localization and low normal tissue background. Clinical imaging studies have also been conducted using ${ }^{123}$ I-labeled anti-CEA minibody for presurgical colorectal cancer patients (7). The anti-CEA minibody demonstrated localization to seven of eight known lesions, 
including three that were not visible by computed tomography (7). $\mathrm{scFv}(25 \mathrm{kDa})$ for a given immunoglobulin exhibits faster clearance kinetics and deeper tumor penetration. However, the absolute dose deposition of scFv is much lower, primarily due to its monovalent binding nature, resulting in lower functional avidity. Diabodies $(55 \mathrm{kDa})$, with their bivalent binding, exhibit better tumor deposition than $\mathrm{scFv}$ and are below the threshold for first-pass renal clearance (8). Larger fragments, such as minibodies $(80 \mathrm{kDa})$, show intermediate clearance rates and reach higher tumor uptake levels (9). Diabodies and minibodies reach their maximum tumor uptakes within 1-6 h of administration in xenograft-bearing mice and, because of rapid blood clearance, tumor-to-blood ratios increase steadily over time and reach high values (>20:1) by $24 \mathrm{~h}$, making these fragments prime candidates for imaging.

The in vivo properties of a slightly larger antibody fragment, scFv-Fc of $105 \mathrm{kDa}(10)$, have been examined. It seems to behave in ways analogous to an intact antibody due to the presence of an intact Fc region. Moreover, certain mutations in the $\mathrm{Fc}$ region that mediate $\mathrm{Fc}$ receptor interactions modulate the clearance kinetics of this antibody fragment. Of particular importance to this work, it is also a variant containing two mutations (H310A/H435Q; Kabat numbering system) and shows similar pharmacokinetics to that of the minibody (10). In addition, high-resolution microPET images are obtained when this antibody fragment is labeled with ${ }^{124} \mathrm{I}$ (10) and ${ }^{64} \mathrm{Cu}$ positron emitters (11). This approach provides a means for tailoring the pharmacokinetics of engineered antibody fragments and should allow for the selection of versions optimized for imaging or therapeutic applications.

Recently, Cai et al applied ${ }^{18} \mathrm{~F}$-labeled T84.66 anti-CEA diabody in colorectal cancer xenograft-bearing mice (12). The results showed rapid and high tumor uptake and fast clearance from the circulation in the xenograft model, as evidenced by both small-animal PET imaging and bio-distribution studies. High-contrast small-animal PET images were obtained as early as $1 \mathrm{~h}$ after injection of the ${ }^{18} \mathrm{~F}-\mathrm{T} 84.66$ diabody, and only a background level of activity accumulation was found in CEA-negative tumors. ${ }^{18} \mathrm{~F}$-labeled diabodies therefore represent a new class of tumor-specific probes for PET, based on targeting cell surface antigen expression.

Some tumor-related antigens are readily internalized, which causes a hammering of imaging signals. Loss of the label in tumors as a result of dehalogenation and the metabolism of proteins labeled subsequent to internalization can be overcome by changing to a more stable conjugation chemistry (sulfosuccinimidyl-3-(4-hydroxyphenyl) propionate) (13). Additional work $(14,15)$ has led to the development of antiHer2 minibodies radiolabeled using ${ }^{64} \mathrm{Cu}$-DOTA, permitting the microPET imaging of Her2-overexpressing xenografts in mice. In this case, internalization of the radiometal-labeled tracer resulted in metabolism and trapping of the radioactivity at the tumor site, maintaining the signal.

Visualization and quantification of Her2 expression by in vivo imaging will probably prove to be an important approach, not only for assessing target availability but also for monitoring response to treatment. Others have also used PET with ${ }^{68} \mathrm{Ga}$-radiolabeled $\mathrm{F}\left(\mathrm{ab}^{\prime}\right) 2$ fragments of trastuzumab to monitor Her2 expression in animal tumors during the course of treatment with 7-allylaminogeldanamycin (Hsp90 inhibitor), showing loss and subsequent recovery of Her2 expression in vivo (16).

\section{SPECT imaging}

SPECT is another type of nuclear medical examination. In some cases, PET may be more sensitive than SPECT, but the latter is more widely available because radioisotope generation technology is longer lasting and far less expensive in SPECT, as is the $\gamma$-scanning equipment.

Angiogenesis or vasculargenesis is very important during the maintenance and development of tumor growth. In vivo SPECT imaging has been used for vascular evaluation with engineered antibodies as agents. SPECT imaging of tumor neo-vascularization with ${ }^{123}$ I-labeled anti-fibronectin ED-B $\mathrm{ScFv}$ dimer in cancer patients has proven the potential of engineered antibodies as radiotracers $(12,17)$. SPECT imaging with iodine-125 or technetium-99m radiolabeling has shown promising results, providing important information. For example, within $30 \mathrm{~min}$ of injecting engineered anti-VEGF antibody (TX3.833) in the tail vein of rats, $>80 \%$ of the dose was transported across the vascular membrane and accumulated in lung tissue (17).

Various SPECT radionuclides have different energies, making it possible to distinguish a panel of biomarker antigens at the same time. On the other hand, PET isotopes all have the same emission, $511 \mathrm{keV}$ annihilation photons. Serial imaging is therefore necessary for the evaluation of different markers. The availability of radionuclides for clinical and research purposes continues to expand, along with their potential applications, and the radioimmunodetection of tumor growth is essential and widely used. A radiolabeled immunoconstruct with enhanced properties for imaging must be of potentially intermediate molecular mass with tumor uptake comparable to intact antibodies, but with clearance times more rapid than the intact IgG, providing improved imaging capabilities.

\section{MRI imaging}

Even though MRI has been regarded as a powerful imaging tool as a result of its non-invasive nature, high spatial resolution and tomographic capabilities, its low signal sensitivity has been a major limitation. When ultra-sensitive magnetic nanoprobes, like magnetism-engineered iron oxide (MEIO), are conjugated with Herceptin, enhanced MRI sensitivity is demonstrated in the detection of breast cancer marker Her2/neu in tumors as small as $~ 50 \mathrm{mg}$ (18). If such nanoprobes can be integrated with engineered antibody fragments that show versatile functions, including targeting moiety, engineered antibody-magnetic nanoprobes will definitely become promising candidates for high-performance MRI imaging agents. As for toxicity, the results of Lee et al (18) show that $\mathrm{Mn}$-doped $\mathrm{MnFe}_{2} \mathrm{O}_{4}$ (MnMEIO), which was the nanoparticle with the highest relativity value (the strongest MR contrast effect), along with MnMEIO-Herceptin, were found to be biologically nontoxic in HeLa and HepG2 cell lines at $200 \mu \mathrm{g} / \mathrm{ml}$. However, in vivo toxicity should be further investigated as no literature exists that well proves the point. 


\section{Optical fluorescence and bioluminescence imaging}

In vivo optical imaging has emerged as a relatively simple, inexpensive method for non-invasively observing biological processes inside a small living animal. For example, a bifunctional anti-CEA diabody-Renilla luciferase fusion protein (Db-Rluc8) was systemically administered in tumorbearing mice (19). The results show that this fusion protein preferentially localized antigen-positive tumors and generated a bioluminescent signal that could be detected in the living mouse. More recently, the anti-CEA diabody was fused to Gaussia luciferase, which offers a fusion protein of a smaller size (Da-Gluc, $90 \mathrm{kDa}$ ) with potentially brighter light output that improves targeting and imaging properties (20).

Near-infrared fluorescent dye conjugated to antibodies against EGFR has also shown promise for the detection of pre-cancers (21), as it provides deeper tissue penetration. Molecular optical-specific imaging using fluorescence-labeled antibodies (22) and indocyanine green N-hydroxysulfosuccinimide ester (ICG-sulfo-Osu)-labeled antibodies (23) has also been demonstrated. Even though no official reviews have been published in this field, we can predict that engineered antibody fragments will give better results for specific fluorescent imaging.

Nanocrystalline semi-conductor materials, named quantum dots (QDs), have become a new class of fluorescent probes for optical imaging. Many efforts have been undertaken to image ligand-receptor interactions utilizing QD-conjugated antibodies to target the receptors (24-27). The primary antibody targets the cell-surface receptors and is then recognized by a biotinylated secondary antibody, which binds a streptavidin-coated QD (28). This sandwich-imaging format leads to a very large molecular complex that may hamper accurate imaging of receptor densities and receptor dynamics. Engineered antibody fragments might be one strategy to minimize the size of the QD-label complex, and can also be covalently conjugated to a QD surface. Intact antibodies, on the other hand, have to be non-covalently complexed to the QDs, usually through biotin-streptavidin conjugates. Although QDs are so far considered to be safe, recent work done by Shiohara et al (29) shows that water-soluble QDs covered with mercapto-undecanoic acid (also known as MUA-QD) affect the cell variability of Vero, HeLa, and primary human hepatocyte cells even at low concentrations. This suggests that further studies on cell type versus QD cell damage must be conducted, since there is currently not enough information about the discharge of QDs from living organisms or on their long-term toxicity.

\section{Ultrasound imaging}

Even though ultrasound is accessible, portable and widely available, it has received less attention than other imaging techniques. However, the development of microbubble contrast agents (the intravenous injection of small amounts of air or gas bubbles that enhance the Doppler signal) (30) makes it a competitive alternative as it has enabled many new possibilities, including molecularly-targeted tumor imaging. For example, a lipid-shelled microbubble engineered with a monoclonal antibody to ICAM-1 can be used as an early indi- cator of atherosclerosis when expressed on the surface of activated endothelial cells, and gives better results as nontargeted microbubbles (31). However, ultrasound microbubble contrast agents have recently been black-labeled by the FDA because of reports of deaths and serious cardiopulmonary reactions following their administration.

\section{Conclusion}

Antibody engineering has changed significantly in the past decade, making smaller recombinant antibody fragments and engineered variants (like diabodies, triabodies, minibodies and single-domain antibodies) a promising alternative to monoclonal antibodies. With innovative technologies, these engineered antibody fragments retain the targeting specificity of whole mAbs, but are more economically available. In addition, by forging them into multivalent and multispecific reagents or linking them to therapeutic payloads for many diagnostic and therapeutic applications, they can posses other superior properties. As these properties allow them to be used for real-time imaging with higher specificity, they will doubtless become very important in this field and, in years to come, will be indispensable as both clinical and research reagents.

\section{References}

1. Holliger P and Hudson PJ: Engineered antibody fragments and the rise of single domains. Nat Biotechnol 23: 1126-1136, 2005.

2. Hudson PJ and Souriau C: Engineered antibodies. Nat Med 9: 129-134, 2003.

3. Nilsson FY and Tolmachev V: Affibody molecules: new protein domains for molecular imaging and targeted tumor therapy. Curr Opin Drug Discov Devel 10: 167-175, 2007.

4. Begent RH, Verhaar MJ, Chester KA, Casey JL, Green AJ, Napier MP, Hope-Stone LD, Cushen N, Keep PA, Johnson CJ, Hawkins RE, Hilson AJ and Robson L: Clinical evidence of efficient tumor targeting based on single-chain Fv antibody selected from a combinatorial library. Nat Med 2: 979-984, 1996.

5. Larson SM, El-Shirbiny AM, Divgi CR, Sgouros G, Finn RD, Tschmelitsch J, Picon A, Whitlow M, Schlom J, Zhang J and Cohen AM: Single chain antigen binding protein (sFv CC49): first human studies in colorectal carcinoma metastatic to liver. Cancer 80: 2458-2468, 1997.

6. Sundaresan G, Yazaki PJ, Shively JE, Finn RD, Larson SM, Raubitschek AA, Williams LE, Chatziioannou AF, Gambhir SS and Wu AM: ${ }^{124}$ I-labeled engineered anti-CEA minibodies and diabodies allow high-contrast, antigen-specific small-animal PET imaging of xenografts in athymic mice. J Nucl Med 44: 1962-1969, 2003.

7. Wong JY, Chu DZ, Williams LE, Yamauchi DM, Ikle DN, Kwok CS, Liu A, Wilczynski S, Colcher D, Yazaki PJ, Shively JE, Wu AM and Raubitschek AA: Pilot trial evaluating an ${ }^{123}$ I-labeled 80-kilodalton engineered anticarcinoembryonic antigen antibody fragment (cT84.66 minibody) in patients with colorectal cancer. Clin Cancer Res 10: 5014-5021, 2004.

8. Huhalov A and Chester KA: Engineered single chain antibody fragments for radioimmunotherapy. Q J Nucl Med Mol Imaging 48: 279-288, 2004.

9. Borsi L, Balza E, Bestagno M, Castellani P, Carnemolla B, Biro A, Leprini A, Sepulveda J, Burrone O, Neri D and Zardi L: Selective targeting of tumoral vasculature: comparison of different formats of an antibody (L19) to the ED-B domain of fibronectin. Int J Cancer 102: 75-85, 2002.

10. Kenanova V, Olafsen T, Crow DM, Sundaresan G, Subbarayan M, Carter NH, Ikle DN, Yazaki PJ, Chatziioannou AF, Gambhir SS, Williams LE, Shively JE, Colcher D, Raubitschek AA and Wu AM: Tailoring the pharmacokinetics and positron emission tomography imaging properties of anti-carcinoembryonic antigen single-chain $\mathrm{Fv}-\mathrm{Fc}$ antibody fragments. Cancer Res 65: 622-631, 2005. 
11. Yazaki PJ, Wu AM, Tsai SW, Williams LE, Ikler DN, Wong JY, Shively JE and Raubitschek AA: Tumor targeting of radiometal labeled anti-CEA recombinant T84.66 diabody and t84.66 minibody: comparison to radioiodinated fragments. Bioconjug Chem 12: 220-228, 2001.

12. Cai W, Olafsen T, Zhang X, Cao Q, Gambhir SS, Williams LE, $\mathrm{Wu} \mathrm{AM}$ and Chen X: PET imaging of colorectal cancer in xenograft-bearing mice by use of an ${ }^{18} \mathrm{~F}$-labeled T84.66 anticarcinoembryonic antigen diabody. J Nucl Med 48: 304-310, 2007.

13. Robinson MK, Doss M, Shaller C, Narayanan D, Marks JD, Adler LP, Gonzalez Trotter DE and Adams GP: Quantitative immuno-positron emission tomography imaging of HER2positive tumor xenografts with an iodine-124 labeled anti-HER2 diabody. Cancer Res 65: 1471-1478, 2005.

14. Olafsen T, Tan GJ, Cheung CW, Yazaki PJ, Park JM, Shively JE, Williams LE, Raubitschek AA, Press MF and Wu AM: Characterization of engineered anti-p185HER-2 (scFv-CH3)2 antibody fragments (minibodies) for tumor targeting. Protein Eng Des Sel 17: 315-323, 2004.

15. Olafsen T, Kenanova VE, Sundaresan G, Anderson AL, Crow D, Yazaki PJ, Li L, Press MF, Gambhir SS, Williams LE, Wong JY, Raubitschek AA, Shively JE and Wu AM: Optimizing radiolabeled engineered anti-p185HER2 antibody fragments for in vivo imaging. Cancer Res 65: 5907-5916, 2005.

16. Smith-Jones PM, Solit DB, Akhurst T, Afroze F, Rosen N and Larson SM: Imaging the pharmacodynamics of HER2 degradation in response to Hsp90 inhibitors. Nat Biotechnol 22: 701-706, 2004.

17. Cai $\mathrm{W}$ and Chen X: Multimodality imaging of vascular endothelial growth factor and vascular endothelial growth factor receptor expression. Front Biosci 12: 4267-4279, 2007.

18. Lee JH, Huh YM, Jun YW, Seo JW, Jang JT, Song HT, Kim S, Cho EJ, Yoon HG, Suh JS and Cheon J: Artificially engineered magnetic nanoparticles for ultra-sensitive molecular imaging. Nat Med 13: 95-99, 2007.

19. Venisnik KM, Olafsen T, Loening AM, Iyer M, Gambhir SS and $\mathrm{Wu}$ AM: Bifunctional antibody-Renilla luciferase fusion protein for in vivo optical detection of tumors. Protein Eng Des Sel 19: 453-460, 2006.

20. Niu G, Xiong Z, Cheng Z, Cai W, Gambhir SS, Xing L and Chen X: In vivo bioluminescence tumor imaging of RGD peptide-modified adenoviral vector encoding firefly luciferase reporter gene. Mol Imaging Biol 9: 126-134, 2007.
21. Sokolov K, Follen M, Aaron J, Pavlova I, Malpica A, Lotan R and Richards-Kortum R: Real-time vital optical imaging of precancer using anti-epidermal growth factor receptor antibodies conjugated to gold nanoparticles. Cancer Res 63: 1999-2004, 2003.

22. Anikijenko P, Vo LT, Murr ER, Carrasco J, McLaren WJ, Chen Q, Thomas SG, Delaney PM and King RG: In vivo detection of small subsurface melanomas in athymic mice using noninvasive fiber optic confocal imaging. J Invest Dermatol 117: 1442-1448, 2001.

23. Ito S, Muguruma N, Kusaka Y, Tadatsu M, Inayama K, Musashi Y, Yano M, Bando T, Honda H, Shimizu I, Ii K, Takesako K, Takeuchi H and Shibamura S: Detection of human gastric cancer in resected specimens using a novel infrared fluorescent anti-human carcinoembryonic antigen antibody with an infrared fluorescence endoscope in vitro. Endoscopy 33: 849-853, 2001.

24. Giepmans BN, Deerinck TJ, Smarr BL, Jones YZ and Ellisman MH: Correlated light and electron microscopic imaging of multiple endogenous proteins using Quantum dots. Nat Methods 2: 743-749, 2005.

25. Lidke DS, Nagy P, Heintzmann R, Arndt-Jovin DJ, Post JN, Grecco HE, Jares-Erijman EA and Jovin TM: Quantum dot ligands provide new insights into erbB/HER receptor-mediated signal transduction. Nat Biotechnol 22: 198-203, 2004.

26. Gao X, Cui Y, Levenson RM, Chung LW and Nie S: In vivo cancer targeting and imaging with semiconductor quantum dots. Nat Biotechnol 22: 969-976, 2004.

27. Dahan M, Levi S, Luccardini C, Rostaing P, Riveau B and Triller A: Diffusion dynamics of glycine receptors revealed by single-quantum dot tracking. Science 302: 442-445, 2003.

28. Wu X, Liu H, Liu J, Haley KN, Treadway JA, Larson JP, Ge N, Peale F and Bruchez MP: Immunofluorescent labeling of cancer marker Her2 and other cellular targets with semiconductor quantum dots. Nat Biotechnol 21: 41-46, 2003.

29. Shiohara A, Hoshino A, Hanaki K, Suzuki K and Yamamoto K: On the cyto-toxicity caused by quantum dots. Microbiol Immunol 48: 669-675, 2004.

30. Liang HD and Blomley MJ: The role of ultrasound in molecular imaging. Br J Radiol 76: S140-S150, 2003.

31. Lanza GM and Wickline SA: Targeted ultrasonic contrast agents for molecular imaging and therapy. Prog Cardiovasc Dis 44: 13-31, 2001. 